like surface. For ordinary moist climates, however, these tests serve as a clear condemnation of all limestones. Even the gritty Kentish Rag (p. 45) comes out badly, though, in combination with the ferruginous sandstones of our Lower Greensand, it has been known to make a road that held well together in dry seasons.

The question of composite roads would be an interesting study in itself. Materials showing great differences under the attrition-test should, of course, not be used in association; but roads made of mixed gravel taken out of streams show good results in many parts of Europe. Similar material is usefully supplied by the glacial gravels nearer home. Teachers of practical geology, as well as all county and borough surveyors, will be grateful to the three authors for providing a remarkably cheap, clear and thoughtful treatise on a subject that the whirligig of time has again made of national importance.

G. A. J. C.

\section{DYNAMO DESIGN.}

Elementary Principles of Continuous Current Dynurro Design. By H. M. Hobart. Pp. $\mathrm{x}+220$. (London: Whittaker and Co.) Price $7 s .6 d$. net.

$\mathrm{T}^{\mathrm{T}}$ is scarcely necessary at this date to recommend 1 a book by Mr. Hobart on the design of direct current dynamo machines; it is safe to say that any production by this author will repay the study of practical men, and the present book forms no exception.

The contrast presented between a volume setting forth the results of the practical experience of a man engaged in actual work and a book evolved out of the inner consciousness of a man who has access only to the theory of the subject is very striking. Books of the former class are comparatively rare, and are correspondingly valuable.

Dealing in a general way with Mr. Hobart's work, the first point that strikes one favourably is the emphasis laid on the necessity of a large amount of application on the part of the student of the principles and methods set forth. These principles and methods must be regarded as the framework on which a designer is to build; and it is folly for him to assume that he is acquainted with the subject unless and until he has gone a long way in completing the structure by his own labour. The value of the book lies in the essential soundness of this framework, more particularly of the fundamental ideas on which it is itself based than on the framework itself. The commercial point of view is not instinctive with designers, and it is of the greatest importance that it should be acquired as soon as possible. For this reason $\mathrm{Mr}$. Hobart has done well to lay stress on the necessity of judging every design by taking into account its first cost as well as its technical merits.

Regarded in this way, the book consists of a series of statements explaining the way in which a dynamo should be considered as a successful machine or the reverse, and of a short account of several methods whereby the designer may himself estimate the first cost.

NO. I940, VOL. 75]
After preliminary chapters on what may be called the practical theory of the continuous current dynamo, Mr. Hobart deals at length with those considerations which form the limits in the design, namely, heating, sparking, and efficiency. Numerous constants and formulæ are given, and miscellaneous information from which efficiencies can be calculated. The sparking data are, naturally, based on the method of reactance voltage, introduced some years ago by the author and Mr. Parshall, although a long list of references is given to those who have contributed to the theory in recent years. This method, or some modification thereof, is so widely used that there is no necessity to describe it here. The constants for dealing with the heating and the efficiency are, perhaps, the least praiseworthy part of the book, or rather not so much the constants as the general method. The treatment in both cases seems somewhat arbitrary; for instance, it is not absolutely certain that the rise in temperature of the armature is proportional to the total watts lostcopper plus iron loss--divided by the area of the cylindrical surface. Again, the method of estimating the iron loss in the armature is distinctly rough. This point has been debated at considerable length in the columns of the technical Press; but in the present writer's opinion there are other methods which certainly give better results. The calculation of the bearing friction and windage is referred to a single curve giving the relation between this loss and the value of $\mathrm{D}^{2} \mathrm{~L}$ at the speed of rooo revolutions per minute; but there seems to be no indication as to how the loss varies with the speed, whether in direct proportion or as the $\mathrm{I} \cdot 5^{\text {th }}$ power of the speed.

These slight discrepancies somewhat diminish the value of the book as a work of reference; but the essential feature of the book consists, as already stated, in the enforcement of a general grasp of the whole problem, commercial as well as technical.

The book contains a large number of tables in which the various calculations are set out; some are filled in and others are left blank for the convenience of the student. It will thus be seen that this is a work which can be thoroughly recommended to the student and the designing engineer alike.

\section{OUR BOOK SHELF.}

Irrigation with Surface and Subterranean Water; and Land Drainage. By W. Gibbons Cox. Pp. viii + 297; illustrated. (Sydney: Angus and Robertson, I906.)

THE author of this book has been engaged for many years in Australia in water supply and irrigation works. There are vast areas of land in that country the soil of which is of the highest fertility, but is barren and comparatively useless because of periodical aridity. The problem of irrigation of the land from the rivers and creeks that flow at times through these districts, and form inexhaustible accumulations of underground water, is treated fully and practically according to the latest and most approved methods.

With all its natural wealth and resources Australia is subject to the great drawback of occasional droughts of greater or less severity. The consequences of one of these droughts is thus graphically described:- "The natural water supply of the dis- 